\title{
Prediction of areas presenting a high radon exhalation potential: A new methodology based on the properties of geological formations and soils
}

\author{
G. lelsch, C. Ferry, G. Tymen ${ }^{1}$ and M.-C. Robe \\ Institut de Protection et de Sûreté Nucléaire, DPRE/SERGD/LEIRPA, \\ BP. 6, 92265 Fontenay-aux-Roses, France \\ ${ }^{1}$ Laboratoire de Recherches Appliquées Atmosphère Hydrosphère, \\ Université de Bretagne Occidentale, UFR Sciences et Techniques, 6 avenue Le Gorgeu, \\ BP. 809, 29285 Brest cedex, France
}

Abstract. A research program carried out since 1997 produced a methodology for predicting areas with a strong potential for radon exhalation at the soil surface. This methodology is based on a quantification of the $\mathrm{Rn}$ exhalation rate, from a precise characterization of the main local geological and pedological parameters that control the radon source and its tansport to the soil/atmosphere interface. It combines a cross mapping analysis of parameters used in a Geographic Information System with a model of the vertical transport of $\mathrm{Rn}$ by diffusion trough the soil. This code (TRACHGEO) calculates the radon flux density at the surface as a function of the properties of the rock and the soil. This approach is yalidated in 4 typical areas with different geological contexts, starting from in situ measurements of radon fluxes and of radon concentrations in dwellings. A lithogeochemical classification of the geological formations as a function of their $U$ contents and their confrontation to $\mathrm{Rn}$ level measurements demonstrate the primordial influence of the $U$ content of the basement on Rn exhalation. This study leads to an initial map of the exhalation potential by assigning a potential class to each lithogeochemistry. Nevertheless, in situ radon measurements reveal a high spatial variability on uraniferous lithologies. Tests made by the TRACHGEO tool show the need to take account of spatial heterogeneity of soils (in addition of geochemistry) to improve the mapping resolution. The TRACHGEO forecasts explain the variability of the Rn exhalation on a larger scale.

\section{INTRODUCTION}

A research program bas been carried out in France since 1997 in order to develop a methodology for predicting areas with a strong potential for exhalation of radon-222 at the surface of the soil [1] [2] [3]. Indeed, the objective is to define areas in which the density of buildings with high radon levels is likely to be highest. Identification of priority areas would then help to target actions taken by the government, and particularly screening measurements in existing buildings.

\section{GENERAL METHODOLOGY}

Our approach is based on the quantification of the radon-222 exhalation rate at the surface of the soil, from the knowledge of the geological and pedological parameters that influence the radon emanation and its migration until the atmosphere. We use a Geographic Information System, combined with a simplified model of the radon migration through the soil, which calculates the radon flux density at the surface, according to the chemical and physical properties of rocks and soils.

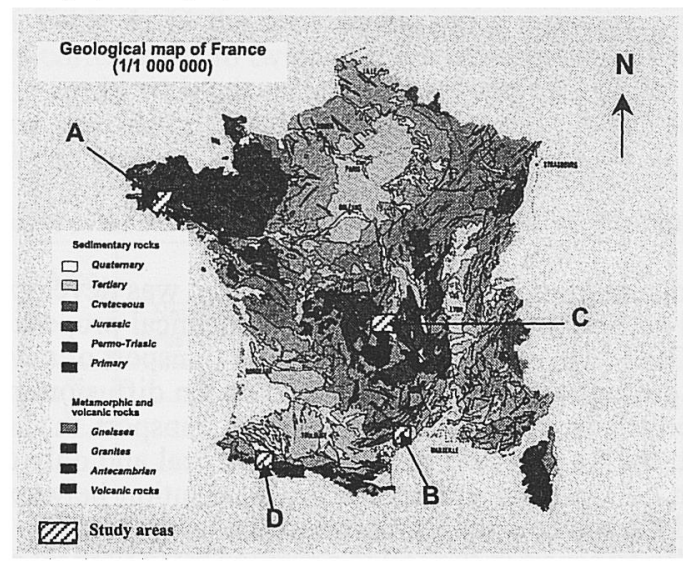

Figure 1. Location of the study areas selected for the methodology validation, on the geological map of France [4].

The main objective was to validate this methodology in 4 typical areas with different geological contexts, 
starting from in situ measurements of the radon exhalation rate at the soil surface. Measurements of the indoor radon concentration were also carried out. Each study area was about $30 \mathrm{~km}$ in breadth and $50 \mathrm{~km}$ in length (Fig. 1). In each transect, measurement paths were chosen in order to run across the different geological formations. The in situ radon level measurements and the acquisition of the geological and pedological data were carried out along these paths. The data was characterized and analyzed at a precise scale $(1 / 50000)$.

\section{DATA ACQUISITION}

\subsection{In situ radon measurements}

Measurement sites were selected along the paths defined in each area, usually at 1- to 3-km intervals. For each geological unit, one point was defined at least. For each site, two measurements of the radon flux density at the soil/atmosphere interface were performed with the « accumulation technique » [5] [6] [7]. The measurement uncertainty is around $20 \%$ and the detection threshold is $1 \mathrm{mBq} \mathrm{m}^{-2} \mathrm{~s}^{-1}$. This data was collected in summer when the weather conditions were fairly stable.

Measurements of the indoor radon concentration were also realized in dwellings, where possible, located near the sites selected for radon exhalation rate measurement. The radon activity was determined by using track-etch detectors (LR115), placed in the main room (ground floor) and exposed for 2 months at least, in winter. The measurement uncertainty varies from $25 \%$ for a concentration below $10 \mathrm{~Bq} \mathrm{\textrm {m } ^ { - 3 }}$, to $4 \%$ for a concentration above $400 \mathrm{~Bq} \mathrm{~m}^{-3}$.

\subsection{Radon source term in the basement rocks}

The uranium content of the rock corresponds to the radon source term in the basement and thus governs the radon exhalation potential. Therefore, our objective was to determine a range of probable $U$ contents for each geological formation of the transects. The rock uranium content was estimated from the geological maps at scale $1 / 50000$ and from the chemical information available on these formations. The geological units were first classified according to their lithology. Then, a probable $U$ content range was assigned to each lithological class, using two different approaches: the first one was direct and based on the chemical analysis of rocks sampled in precise geological units (units of the transects completed by analyses of other geological formations corresponding to the same lithology) and the second one (indirect or « lithogeochemical ») used estimations of the variability of $U$ contents for a given lithology, published in the literature.

\subsection{Soils characteristics}

A soil sample was taken in each radon measurement site (at $50 \mathrm{~cm}$ depth) in order to determine its volumetric moisture and porosity (gravimetric method). The soil thickness was estimated from pedological drillings also carried out on each site. Furthermore, each soil sample radium-226 activity was analysed by gamma-ray spectrometry, using a Germanium hyper-pure detector, of N-type (61.9 mm crystal diameter), with a $40 \%$ relative efficiency and a resolution value of $1.95 \mathrm{keV}$ at $1.33 \mathrm{MeV}$. The measurement uncertainty is about $10 \%$.

\section{DATA ANALYSIS}

\subsection{The TRACHGEO model}

A simplified model of the radon migration through a soil column, was developed in order to calculate the $\mathrm{Rn}$ exhalation rate at the soil surface, from the physical and chemical properties of the rock and the soil. This model, named TRACHGEO (which stands, in French, for transport of radon through a homogeneols layer limited at its base by a geological formation), is based on $\mathrm{Rn}$ diffusion in the pore space of the soil. It is a simplified version derived from the non-steady radon transport in the unsaturated zone model, TRACI [8]. We assume that: the Rn transport in the soil is vertical and only due to diffusion in the pore space; there is no adsorption on the solid grains; the $\mathrm{Rn}$ distribution between liquid and gas phases is governed by Henry's law and the soil column is homogeneous.

In this case, the steady-state $\mathrm{Rn}$ transport in the soil is governed by ( $\mathrm{z}$ vertical axis, directed upward): 


$$
D \cdot \frac{d^{2} C}{d z^{2}}-\lambda \cdot C+\lambda \cdot \frac{\rho d \cdot E \cdot C_{R a}}{p_{e f f}}=0 \quad[9] ;
$$

where $\mathrm{C}$ is the $\mathrm{Rn}$ concentration in the gas phase $\left(\mathrm{Bq} \mathrm{m}^{-3}\right) ; \mathrm{D}$, the pore average $\mathrm{Rn}$ diffusion coefficient $\left(\mathrm{m}^{2} \mathrm{~s}^{-1}\right)$; $\mathrm{E}$, the $\mathrm{Rn}$ emanation factor $(-) ; \rho_{\mathrm{d}}$, the dry bulk density of the soil $\left(\mathrm{kg} \mathrm{m}^{-3}\right) ; \mathrm{C}_{\mathrm{Ra}}$, the radium concentration in solid material $\left(\mathrm{Bq} \mathrm{kg}^{-1}\right) ; \lambda$, the radioactive decay constant of $\mathrm{Rn}\left(2.110^{-6} \mathrm{~s}^{-1}\right)$. The effective porosity, $\mathrm{p}_{\text {eff }}(-)$, is given by [9]:

$$
p_{e f f}=p \cdot(1-m+k H \cdot m)
$$

where $\mathrm{p}$ is the total porosity of the soil $(-)$; $\mathrm{m}$, the soil moisture saturation (-) and $\mathrm{k}_{\mathrm{H}}$, the Henry's law constant $(0.25)$.

At the surface of the soil, the radon concentration is zero. Radon concentration in the gas phase of the underlying rock, $\mathrm{C}^{\mathrm{r}}$ is supposed not to be affected by transport and is given by:

$$
C^{r}=\frac{\rho_{d}^{r} \cdot E^{r} C_{R a}^{r}}{(1-m+k H \cdot m) \cdot p^{r}}
$$

where $r$ refers to the rock properties (here, it is assumed that the rock moisture saturation is equal to the soil moisture saturation). By continuity, it imposes the Rn concentration in the soil gas phase at the soil rock interface.

The $\mathrm{Rn}$ flux at the soil surface $\mathrm{F}$ is obtained by solving the $\mathrm{Rn}$ transport equation with the boundary conditions given above:

where

$$
F=p_{e f f} \cdot \sqrt{\lambda \cdot D} \cdot\left(\frac{C^{s}}{t h\left(H / l_{d}\right)}+\frac{C^{r}-C^{s}}{s h\left(H / l_{d}\right)}\right)
$$

$$
C^{s}=\frac{\rho d \cdot E \cdot C_{R a}}{(1-m+k H \cdot m) \cdot p}
$$

$l=\sqrt{\frac{D}{\lambda}}$ is the Rn diffusion length in the soil (m) and $\mathrm{H}$, the total height of the soil column (m).

The Rn pore average diffusion coefficient in the soil used in TRACHGEO, is given by [9]:

$$
D=p \cdot D_{o} \cdot \exp \left(-6 \cdot m \cdot p-6 \cdot m^{14 p}\right)
$$

where $D_{0}$ is the $R n$ diffusion coefficient in free air $\left(1.110^{-5} \mathrm{~m}^{2} \mathrm{~s}^{-1}\right)$.

\subsection{Geographic Information System}

A Geographic Information System (G.I.S.) was used to analyze the spatial variations of the different information layers constituted by the geological and pedological data and the radon levels.

\section{RESULTS AND DISCUSSION}

The results of the radon level measurements (flux density at the soil surface and indoor concentration) are reported for each area in Table 1 . In the area A, the radon exhalation rate is highly variable (9-837

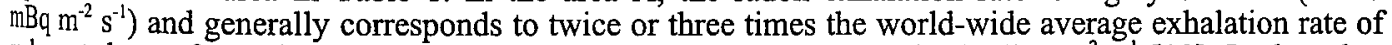
radon at the surface of the earth, which is estimated between 16 and $26 \mathrm{mBq} \mathrm{m}^{-2} \mathrm{~s}^{-1}$ [10]. In the other transects, the Rn exhalation rates do not generally exceed $90 \mathrm{mBq} \mathrm{m}^{-2} \mathrm{~s}^{-1}$ and the mean $\mathrm{Rn}$ flux is similar to the mean value over the continents.

Table 1. Results of the Rn measurements realized at the soil surface in the 4 study areas.

\begin{tabular}{|c|c|c|c|c|}
\hline \multirow{2}{*}{ Area } & \multicolumn{4}{|c|}{ Rn flux density (mBq m-2 s-1) } \\
\cline { 2 - 5 } & $\begin{array}{c}\text { Number of } \\
\text { measurements }\end{array}$ & Range & $\begin{array}{c}\text { Geometric } \\
\text { mean }\end{array}$ & $\begin{array}{c}\text { \% of values } \geq \\
100 \mathrm{mBq} \mathrm{m}^{-2} \mathrm{~s}^{-1}\end{array}$ \\
\hline A & 85 & $9-837$ & 52 & 20 \\
\hline B & 39 & $2-77$ & 10 & 0 \\
\hline C & 35 & $6-87$ & 18 & 0 \\
\hline D & 31 & $3-300$ & 11 & 3 \\
\hline
\end{tabular}

The indoor concentrations show strong variations from 8 to $2896 \mathrm{~Bq} \mathrm{~m}^{-3}$. The proportions of houses presenting $\mathrm{Rn}$ concentrations greater than or equal to $1000 \mathrm{~Bq} \mathrm{~m}^{-3}$ (the French intervention limit, as an 
annual average) and of houses showing concentrations greater than or equal to $400 \mathrm{~Bq} \mathrm{~m}^{-3}$ (the French precaution limit, as an annual average, and the European reference limit) and below $1000 \mathrm{~Bq} \mathrm{~m}^{-3}$ differ significantly between the 4 areas. The highest levels are essentially observed in the transect $A$.

The largest variations of radon levels are observed in the transect $A$, therefore we illustrate our main results by those obtained in this area (Fig. 2).

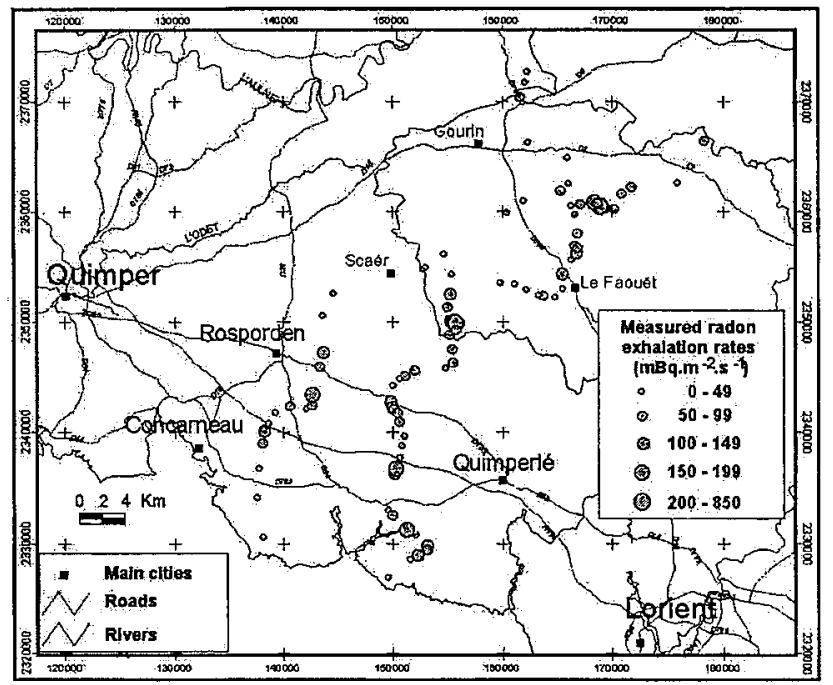

Figure 2. Area A: results of the radon exhalation rate measurements. The measurement sites were selected along a transect oriented NNE-SSW, which runs across the different geological formations observed in the area.

Firstly, the comparison between radon levels measured on the field and lithogeochemistry (U contents) shows that the radon source term of the lithologies, is the primary parameter that controls the spatial variations of radon exhalation rates. It is possible to classify a lithogeochemistry (lithology associated with a range of probable $U$ contents) according to its radon exhalation potential. An example of such a classification is given in Table 2 and is realized by comparing the ranges of the Rn flux densities and of the indoor Rn concentrations measured on each lithogeochemical type. This classification can lead to a map of the radon exhalation potential: an example is given in figure 3 for the area A.

Table 2. Classification of the Rn potential of the lithologies according to their $U$ content and the Rn measurements realized on the 4 study areas. The proportions are relative to the number of measurements performed on each class.

\begin{tabular}{|c|c|c|c|c|}
\hline & $\begin{array}{c}\text { Class I } \\
\text { Very Iow } \\
\text { potential }\end{array}$ & $\begin{array}{c}\text { Class II } \\
\text { Low } \\
\text { potential }\end{array}$ & $\begin{array}{c}\text { Class III } \\
\text { Moderate } \\
\text { potential }\end{array}$ & $\begin{array}{c}\text { Class IV } \\
\text { Fligh } \\
\text { potential }\end{array}$ \\
\hline $\begin{array}{c}\text { Mean U content of the lithologies (ppm; mean for each } \\
\text { geological unit) }\end{array}$ & $\leq 2$ & $\leq 4$ & $\leq 8$ & $\leq 20$ \\
\hline Rn exhalation rate at the soil surface $\geq 100 \mathrm{mBq} \mathrm{m}^{-2} \mathrm{~s}^{-1}$ & $0 \%$ & $<5 \%$ & $<5 \%$ & $30 \%$ \\
\hline Indoor Rn concentration $\geq 400 \mathrm{~Bq} \mathrm{~m}^{-3}$ & $<10 \%$ & $<10 \%$ & $15 \%$ & $30 \%$ \\
\hline Indoor Rn concentration $\geq 1000 \mathrm{~Bq} \mathrm{~m}^{-3}$ & $0 \%$ & $0 \%$ & $0 \%$ & $15 \%$ \\
\hline
\end{tabular}

Nevertheless, we can observe that the radon fluxes are highly variable for a given lithogeochemical type, in particular on uraniferous lithologies corresponding to the high exhalation potential class according io our lithogeochemical classification. Therefore, the exhalation potential mapping that can be realized from the study of the basement geochemistry sometimes over-estimates this potential. The forecasts obtained by TRACHGEO tests show the need to take account of spatial heterogeneity of soils (in addition of geochemistry) to improve the mapping resolution: the theoretical fluxes allow us to explain the spatial variability of the radon exhalation on a larger scale. Therefore, we can estimate a radon exhalation potential for each study site, from the TRACHGEO forecasts. The figure 4 illustrates the theoretical fluxes thus determined in the transect $A$. We can note that this map allows us to obtain forecasts in good agreement with the measurements (Fig. 2) and which are more precise than on the first map of the $\mathrm{Rn}$ exhalation potential only assessed by the lithogeochemical study (Fig. 3). The vast majority of our results 
(75\% of the sites studied in the 4 areas) are in good agreement with observations in the field. However, our estimations largely over-estimate the $\mathrm{Rn}$ exhalation rate for $22 \%$ of the sites. We can also note that a very low proportion of sites $(3 \%)$ presenting a high exhalation potential, cannot be identified by TRACHGEO forecasts: most of these sites are located in faulted areas, suggesting that exhalation variations may be caused by structural anomalies. Indeed, the $\mathrm{Rn}$ transport by advection is not taken into account in our approach ( $R n$ migration only by diffusion).

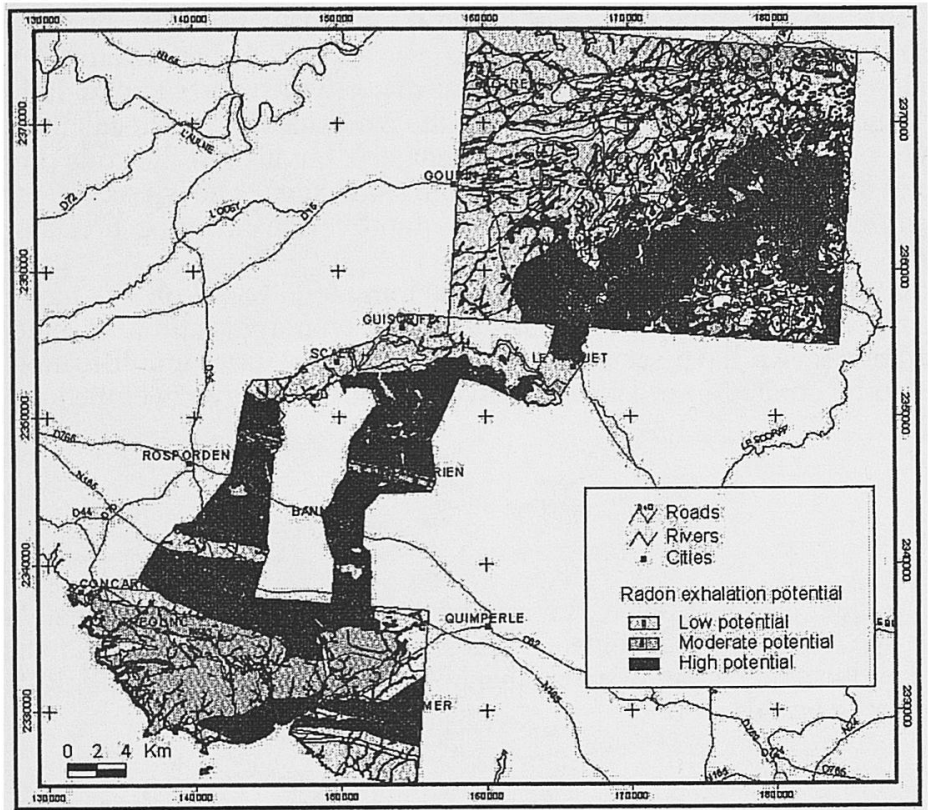

Figure 3. Area A: map of the Rn exhalation potential estimated by comparing the lithogeochemistry of the basement rocks $(U$ contents of the geological formations mapped at the scale 1/50 000) and the range of Rn levels (fluxes at the soil surface and indoor concentrations) measured on each lithogeochemical type (see text for details).

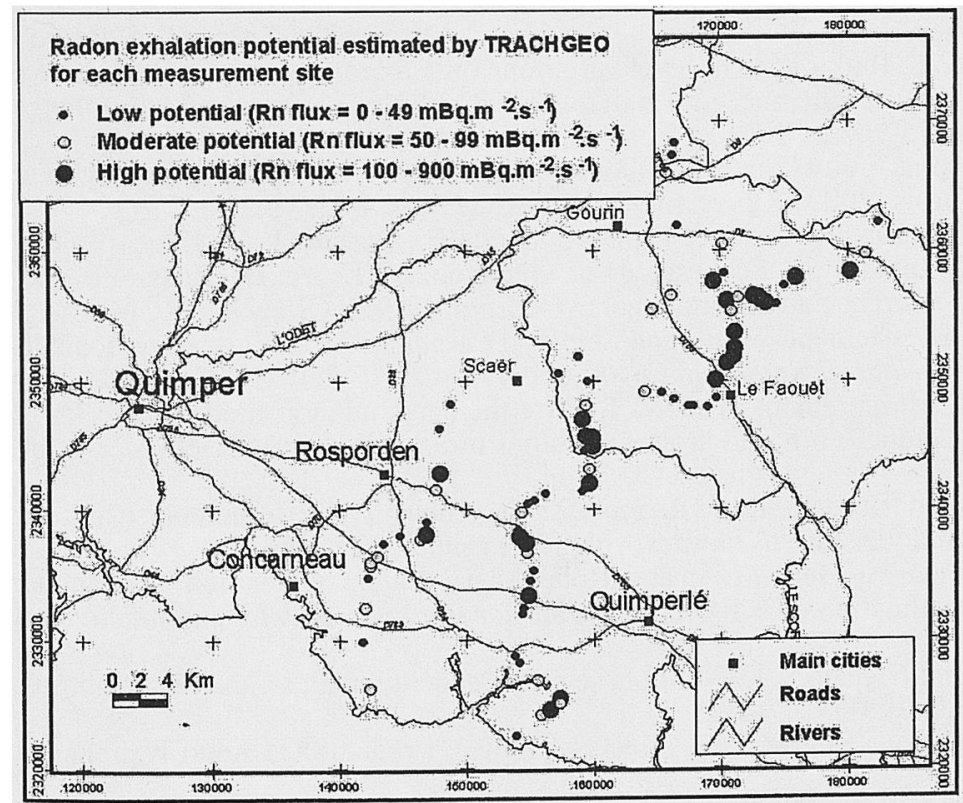

Figure 4. Area A: map of the Rn exhalation potential estimated by TRACHGEO model for each study site. The model takes into account the basement lithogeochemistry and the soils properties. 


\section{CONCLUSIONS}

The proposed methodology is validated on the 4 areas selected for their different geological contexts.

The comparison between lithogeochemical maps and the spatial variations of radon levels demonstrates the primordial influence of the $\mathrm{U}$ content of the basement on the $\mathrm{Rn}$ exhalation, showing that such a geochemical study is a first essential analysis step. It is possible to deduce an initial mapping of the exhalation potential by assigning a potential class to each defined lithogeochemistry. Indeed, the highest radon levels ( $\geq 100 \mathrm{mBq} \mathrm{m}^{-2} \mathrm{~s}^{-1}$ at the surface of the soil) are mostly observed on lithologies whose mean uranium content can exceed $8 \mathrm{ppm}$ or so. It should also be noted that dwellings presenting high Rn concentrations (values above $1000 \mathrm{~Bq} \mathrm{~m}^{-3}$ and the vast majority of values above $400 \mathrm{~Bq} \mathrm{~m}^{-3}$ ) are located on those particular lithogeochemistries. Furthermore, the Rn exhalation rates calculated by TRACHGEO which takes account, not only of the basement geochemistry, but also of the soils properties, are in good agreement with the in situ measurements for $75 \%$ of the study sites. The TRACHGEO model, associated with a Geographic Information System, allows us to improve the mapping precision of $\mathrm{Rn}$ exhalation potential assessment.

Our final objective is now to develop an operational mapping tool, based on this methodology in order to draw predictive maps of radon exhalation potential that would constitute a guide for the $\mathrm{Rn}$ risk management. Nevertheless, we have seen that the exhalation potential amplification factor induced by fracturing remained to be studied in order to improve the methodology developed so far which ignored this phenomenon.

\section{Acknowledgments}

This work was supported by the French Environment and Health Departments. We are particularly grateful to P. Curmi, M. Lamandé, S. Douma, C. Ducommun who carried out soil mapping and described pedological profiles on the study areas. We also thank A. Beneito, D. Haristoy, P. Richon and A Thoreux for their help and remarks on this work.

\section{References}

[1] Ielsch G. , Thiéblemont D. , Perrin J. and Tymen G. Geophysical and geochemical tools for radon mapping on a regional scale. EOS, Transactions, American Geophysical Union, 1999 Fall Meeting, vol. 80 , No. 46, November 16, 1999/Supplement.

[2] Ielsch G. , Thiéblemont D. Labed V., Richon P., Tymen G., Ferry C., Robé M.-C., Baubron J.C. and Béchennec F. Radon $\left({ }^{223} \mathrm{Rn}\right)$ level variations on a regional scale : influence of the basement trace elements (U, Th) geochemistry on radon exhalation rates. Journal of Environmental Radioactivity, vol. 53 (2001), 75-90.

[3] Ielsch, G. Mise au point d'une méthodologie prédictive des zones à fort potentiel d'exhalation du radon. $\mathrm{PhD}$ Thesis (2000), Université de Bretagne Occidentale (Brest), $276 \mathrm{p}$.

[4] Chantraine J., Autran A., Cavelier C., Alabouvette B., Barféty J.-C., Cecca F., Clozier L., DebrandPassard S., Dubreuilh J., Feybesse J.-L, Guennoc P., Ledru P., Rossi Ph and Ternet Y. Carte géologique de la France au millionième, $6^{\text {me }}$ édition (1996). Orléans: BRGM.

[5] Wilkening M.H., Clements W.E. and Stanley D. Radon-222 flux measurements in widely separated regions. In: The Natural Radiation Environment II ; CONF-720805-P2, (1972), 717-730.

[6] Wilkening M. Measurement of radon flux by the accumulation method. In : Workshop on methods for measuring radiation in and around uranium mills, Albuquerque, NM, 23-26 May. Wilkening et al., 1972;

[7] Kearney P.D and Krueger D.A. Radon 222 flux density measurements using an accumulator: an alternative technique. Health Physics, vol. 53(5) (1983), 525-526.

[8] Ferry C., Richon P., Beneito A. and Robé M.-C. Radon exhalation from uranium mill tailings. Experimental validation of a 1-D model. Journal of Environmental Radioactivity, vol. 54(1) (2001), 99-108.

[9] Rogers V.C. and Nielson K.K. Multiphase radon generation and transport in porous materials. Health Physics, vol. 60 (1991), 807-815.

[10] UNSCEAR Report. Sources and effects of ionizing radiation, United Nations, New York, (1993), $922 \mathrm{p}$. 